\title{
Geographic variability of Octopus insularis diet: from oceanic island to continental populations
}

\author{
Tatiana S. Leite ${ }^{1, *}$, Allan T. Batista ${ }^{2}$, Françoise D. Lima $^{2}$, Jaciana C. Barbosa ${ }^{1}$, \\ Jennifer Mather ${ }^{3}$
}

${ }^{1}$ Department of Oceanography and Limnology, Federal University of Rio Grande do Norte, Via Costeira, CEP 59014-100 Natal, RN, Brazil

${ }^{2}$ Ecology Pos-Graduation, Federal University of Rio Grande do Norte, Via Costeira, CEP 59014-100 Natal, RN, Brazil ${ }^{3}$ Psychology Department, University of Lethbridge, Lethbridge AB T1K 3M4, Canada

\begin{abstract}
A predator's choice of prey can be affected by many factors. We evaluated various influences on population dietary composition, individual specialization and size of prey in Octopus insularis populations from 2 continental and 4 insular locations. We expected that habitat diversity would lead to diet heterogeneity. Furthermore, in keeping with MacArthur \& Wilson's (1967) theory of island biogeography, we expected that diet diversity would be lower around islands than on the coast of the mainland. Both predictions were confirmed when prey remains from octopus middens were examined. The 2 continental areas exhibited a richer habitat diversity and a wider variety of prey. Niche widths in the continental areas were 2.42 and 2.03 , with the lowest niche widths exhibited by the population from the most distant oceanic islands $(1.30,0.85)$. We found variation in the proportion of specialist relative to generalist individuals across areas based on the proportional similarity index. The correlation between habitat diversity and niche width $\left(\mathrm{R}^{2}=0.84\right)$ was highly significant, as was distance from the continental shelf and niche width $\left(\mathrm{R}^{2}=0.89\right)$. This study reaffirms the central position of octopuses in the nearshore benthic ecosystem, and supports MacArthur \& Wilson's (1967) prediction of a lower diversity of species on islands - which applies not only to the species themselves, but also indirectly for the diet of their predators.
\end{abstract}

KEY WORDS: Octopus $\cdot$ Feeding niches $\cdot$ Diet $\cdot$ Population

\section{INTRODUCTION}

The choice of prey species is an important decision for any animal-one which can be influenced by a number of factors such as the existence of prey patches, prey availability and abundance, and the energy demand associated with prey capture and handling (Stephens et al. 2007). In general, an animal can exhibit 1 of 2 main predatory strategies: opportunist (generalist) or selective (specialist) (Jaksi 1989). A generalist predator will take all prey in the same relative abundance as they occur in the habitats in which it hunts. Thus, its diet will correlate with the profile of prey abundance, weighted by body size. In contrast, a specialist will take prey in a different pro-

*Corresponding author: leite_ts@yahoo.com.br portion than their availability in the environment, and likely from a narrower range of species. The octopus is considered to be an opportunist/generalist predator, feeding on a wide variety of benthic prey consisting mainly of molluscs and crustaceans (Nixon 1987). However, Scheel \& Anderson (2012) documented differences in prey choices of Enteroctopus dofleini Wülker, 1910, in populations from the Pacific coast of North America, while Mather et al. (2012) observed the same for Octopus cf. vulgaris Cuvier 1797, O. cyanea Gray, 1849 and E. dofleini from similar habitats on several oceanic islands. In addition, Anderson et al. (2008) documented large differences amongst individuals of the same species $(O$. cf. vulgaris) living in a restricted area in Bonaire in the same

() The authors 2016. Open Access under Creative Commons by Attribution Licence. Use, distribution and reproduction are unrestricted. Authors and original publication must be credited. 
general habitat, and labeled the species as a 'specializing generalist'.

It is difficult to trace the many influences that might cause a generalist species to make distinct choices in different populations. One major influence is prey availability; Ambrose (1984) found that preference measured in the laboratory and availability assessed in the field jointly influenced the choice of $O$. bimaculatus Verrill, 1883 in California, resulting in one gastropod species being a major component of its diet. Scheel et al. (2007) assessed both prey availability and choice in E. dofleini in an Alaska rocky beach, and found evidence for preference for 2 crab species: Cancer oregonensis Dana, 1852 and Telmessus cheiragonus Tilesius, 1812, despite the larger proportion of other crab species in the prey biomass. In fact, $O$. rubescens Berry, 1953 from Washington selected crabs rather than bivalves as prey in a laboratory experiment-even when the time devoted to extracting the crabs was longer and the amount of energy obtained from crabs was less than from bivalves (Onthank \& Cowles 2011). A study examining the diet of E. megalocyanthus Gould, 1852 based on stomach contents showed that they foraged predominantly on crustaceans, molluscs and teleost fish, with the size of the octopus being a better predictor than gender and fishing zone for variance in the composition of the diet (Ibáñez \& Chong 2008). In addition, in a habitat with diverse substrates, individual differences in prey choice might be influenced by the personalities of the individual octopus (Mather et al. 2012), which can vary widely (Mather \& Anderson 1993).

None of the above-mentioned studies examined a single predator species whose distribution encompasses a wide area as well as variety of different habitats. Such a comparison is possible for O. insularis Leite \& Haimovici 2008, a dominant member of the benthic marine ecosystem of the Brazilian coast (Leite et al. 2008). It can be found around the oceanic islands of Fernando de Noronha, Saint Peter and Saint Paul, and the Rocas Atoll, all off the northern coast of Brazil. The majority of their diet in these areas consists of small crabs; the population at the Fernando de Noronha Archipelago has been described as a 'specialized predator' and a 'time minimizing hunter', feeding on small crabs and searching intensively for food during short foraging trips (Leite et al. 2009a,b). O. insularis has been studied in other habitats, including biogenic and rocky reefs on the continental edge, and most recently on the southern oceanic islands of Trindade and Martim Vaz Archipelago (Leite et al. 2012). Comparisons of the foraging behavior across these locations provides an opportunity to study many different influences on the dietary composition of this economically important octopus species.

What other influence besides prey abundance might predict the prey consumption of a generalist species such as $O$. insularis? One influence would be the ability of the species to explore and find prey from different habitats and microhabitats. For instance, bivalves are typically filter feeders, and thus are usually buried in sandy and muddy substrates (Gosling 2003), and marine gastropods are commonly found as benthic epifauna and exhibit a wide variety of feeding styles (herbivores, carnivores, scavengers, deposit feeders and suspension feeders) (Karleskint et al. 2010). In contrast, decapods such as xanthid and majid crabs are found in rocky calcareous and coral substrates on oceanic islands (Melo 1996). A generalist predator with its heavy dependence on learning (see Darmaillacq et al. 2014) might take advantage of a local preponderance of specific prey (see Scheel \& Anderson 2012). Yet if the habitat is varied, as it is in Bonaire (Anderson et al. 2008), the personality of individuals and/or the development of learned hunting behavior (Mather et al. 2014) might dictate the microhabitat that each chooses, and thus the prey they ultimately select.

Another ecological influence on prey choice is the diversity of available prey species. Such biodiversity decreases from the tropics to the temperate oceans (Gaston 2000). In addition, the theory of island biogeography (MacArthur \& Wilson 1967), usually used to describe land-based animals, suggests that small, isolated oceanic islands such as Saint Peter and Saint Paul and the Trindade Archipelago should have a smaller variety of potential prey species. In this case, the selection of prey by octopuses would be narrower and more similar among individuals, regardless of their individual characteristics. Some evidence for this is the exclusive choice of 5 decapod crustaceans by O. cyanea in Hawaii (Mather 2011).

Taken together, this information leads to several predictions regarding the diet of $O$. insularis at 6 sites along the Brazilian coast ( 2 continental and 4 insular locations). The first is that prey composition will differ across different habitat types (e.g. sandy, rocky substrate, coral reefs), therefore the heterogeneity of diet amongst individuals will increase if the octopus population has a greater diversity of habitat to exploit. The second is that the diversity and size of chosen prey will be influenced by distance from the continental shelf and prey will be less diverse (following the island theory) and larger at greater distances from the continent. These hypotheses predict that in 


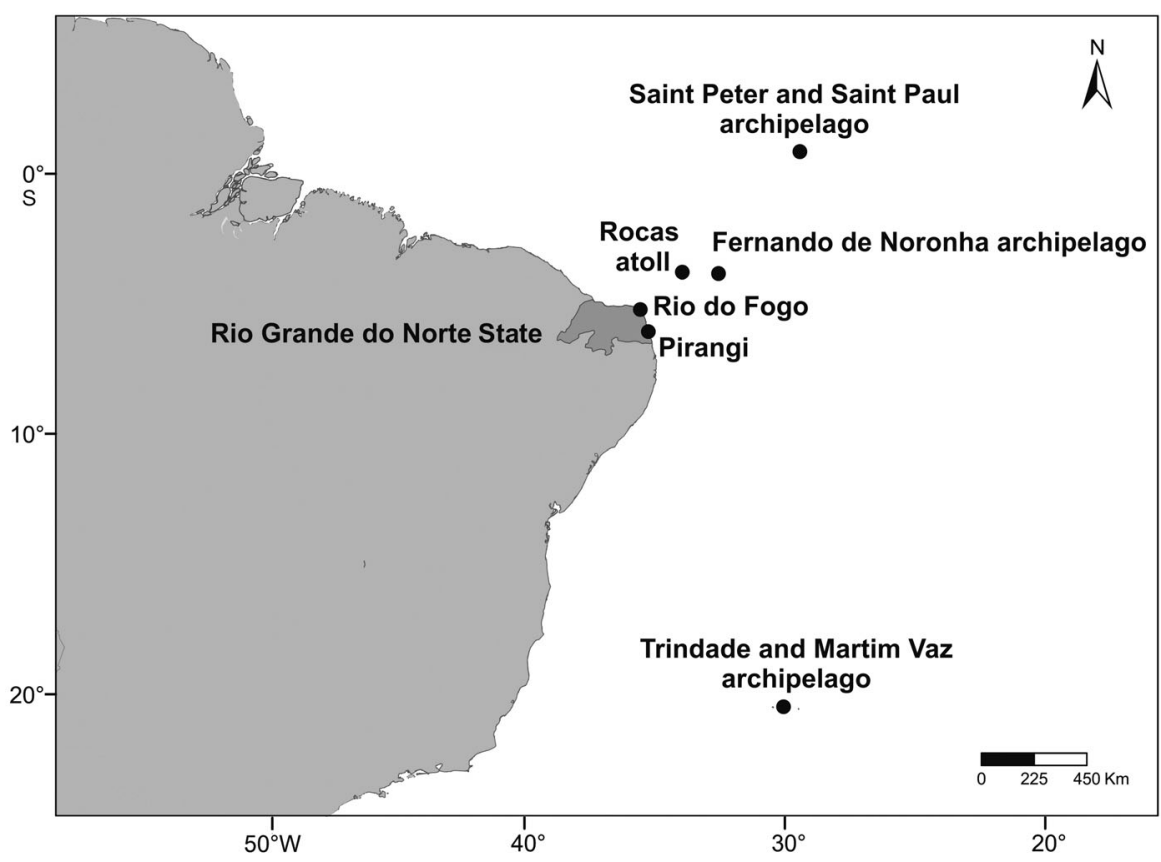

Fig. 1. Study areas on the Brazilian oceanic islands and along the continental coast

areas with lower prey diversity and abundance, a predator should change its feeding strategy to capture few but larger prey items (energy maximizer; Scheel et al. 2007), instead of a higher number of smaller ones (time minimizer; Leite et al. 2009b).

\section{MATERIALS AND METHODS}

Data for this study were obtained from 6 Octopus insularis populations in Brazil; 4 from oceanic islands: Rocas Atoll, and Fernando de Noronha, Saint Peter and Saint Paul, and Trindade and Martim Vaz Archipelagos, and 2 from the northeastern Brazilian coast off Rio Grande do Norte State (Pirangi and Rio do Fogo) (Fig. 1, Table 1). In all populations, prey remains were collected from octopus middens. Octopuses ranged in size from juveniles (mantle length, $\mathrm{ML}=50 \mathrm{~mm}$ ) to adults $(\mathrm{ML}=166 \mathrm{~mm})$, thus reflecting a diet representative of the whole population.

\section{Characterization of diet and habitat}

The methodology for data collection was standardized across all locations. Octopuses were located during walks on emerged rocks on the nearshore and by snorkeling and SCUBA diving between depths of 0.3 and $30 \mathrm{~m}$ in all areas. Once an octopus was detected, information about its size, and the depth and substrate where it was located were recorded. Octopus size was divided into 4 classes: extra small (XS), $\mathrm{ML}<50 \mathrm{~mm}$; small (S), ML 50 to $80 \mathrm{~mm}$; medium (M), ML 80 to $100 \mathrm{~mm}$; and large (L), ML > $100 \mathrm{~mm}$. Habitat data were collected in situ from all areas. The methodology included classification of the substrate around the dens into 11 categories: sandstone reef, rocky, coral, flat biogenic reef, algae patches, seagrass, rubble, muddy, sandy patches, tide pools, intertidal rocky bed (see Table 1).

Diet was determined from fresh, hard-bodied prey remains left in midden heaps in front of octopus dens, which were identified by the simultaneous presence of the octopus and fresh prey remains (mollusc and crustacean) (Leite et al. 2009b). To consider a prey item as a single individual, we used carapaces for crustaceans, shells for gastropods and either both valves or single valve with no match for bivalves. Prey remains were judged to be fresh if there was no algae growing on the inner surface (which would mean it was only 1 or $2 \mathrm{~d}$ old) and was unweathered (Mather 1991). All hard-bodied prey remains in a $0.5 \mathrm{~m}$ diameter area around the den were also collected (Leite et al. 2009b). Molluscs were identified following Rios (1994) and crustaceans following Melo (1996). Some dens were investigated for prey remains more than once, but the octopuses were counted on only one occasion. Lengths and widths (in $\mathrm{mm}$ ) of bivalve and gastropod shells and crab carapaces were measured.

\section{Evaluation and statistical analyses}

For this study, we used information previously published by the first author and collaborators about octopus diet from Fernando de Noronha Archipelago (473 prey remains; Leite et al. 2009a,b) Rocas Atoll (451 prey remains; Bouth et al. 2011), and Trindade and Martim Vaz Archipelago (42 prey items; Leite et al. 2012). We also included recent data collected from the Rio Grande do Norte Brazilian coast (Pirangi: 38 prey remains; Rio do Fogo: 456 prey remains), and Saint Peter and Saint Paul Archipelagos (16 prey remains). The number of the prey remains cited above refers to the total number of individuals in prey 


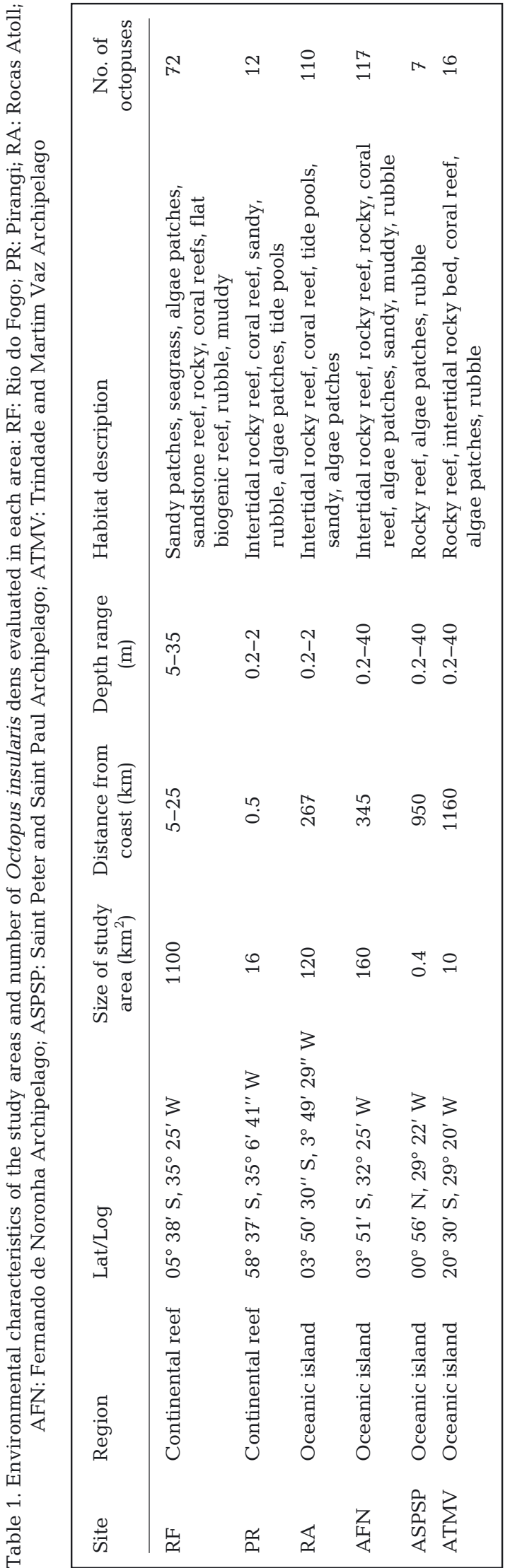

remains found in each area. Scheel \& Anderson (2012) found an influence of items per midden on niche width and proportional similarity indices; therefore, only those octopuses at whose dens we found 4 or more prey items were selected for calculations of niche width, proportional similarity, and number of specialist and generalist individuals in each population (see below). These correspond to the remains of 323 prey items from Fernando de Noronha Archipelago (29 dens), 346 from Rocas Atoll (29 dens), 4 from Saint Peter and Saint Paul Archipelago (1 den), 14 from Trindade (2 dens), 34 from Pirangi ( 7 dens) and 447 from Rio do Fogo (31 dens).

For the analyses, prey species were grouped by genera since the distinctions between species were often small. A 1-way ANOVA and post hoc Tukey's HSD test were used to analyze differences in sizes of the most frequent prey from each sampled site, and among the prey sizes consumed by the octopus size categories at each sampled site. To quantify and compare the number of prey species and niche width of each population, we used Margalef's richness $\left(D_{\mathrm{Mg}}=\frac{(S-1)}{\ln N}\right.$, where $N=$ the total number of individuals in the sample and $S=$ the number of species recorded) and total niche width (TNW) indices (TNW $=-\sum_{j} q_{j} \ln q_{j}$, where $q_{j}$ is the proportion of the $j^{\text {th }}$ resource category in the population's niche), based on the Shannon-Weaver biodiversity index and proposed by Roughgarden (1979). Margalef's index was calculated with the paleontological statistics software package for education and data analysis (PAST; Hammer et al. 2001), using the total number of the prey items found in each sampled areas, while TNW was calculated with IndSpec v.1.0 (Bolnick et al. 2002) using only those dens containing 4 or more prey items.

To represent and compare population feeding niches among the study areas, we performed a nonmetric multidimensional scaling (nMDS) ordination analysis (Clarke \& Warwick 2001), with number of restarts $=25$ and minimum stress $=0.01$. The similarity matrix was based on prey genera abundance in each den, $\log (x+1)$ transformed using the BrayCurtis index (Bray \& Curtis 1957). We used ANOSIM to test for significant differences among groups, followed by a pairwise test $(\mathrm{R}>0.5)$. We then performed SIMPER analysis to evaluate the contribution of typical prey genera to each group (i.e. similarity), using the Bray-Curtis measure of similarity. This methodology allowed us to identify the species that were most important in creating the observed pattern. All multivariate analyses were performed with the PRIMER v.6.0 program (PRIMER-E). 
For the analysis below, generalist refers to individuals that eat similar prey species as that of the population as a whole, while specialist refers to an individual that eats different prey species compared to the population average. To quantify the number of specialist and generalist individuals in each population, we used 2 methodologies. The first was the proportional similarity index $\left(\mathrm{PS}_{i}\right)$ proposed by Schoener (1968), which measures the degree of specialization of an individual based on similarities between the individual's diet and that of the overall population (Bolnick et al. 2002). Individuals were considered specialists if $\mathrm{PS}_{i}<$ 0.5, and generalist if $\mathrm{PS}_{i} \geq 0.5$ (Mather et al. 2012). A chi-squared test was used to evaluate significant differences between the proportion of specialist and generalist individuals among the octopus size categories in each sampled site. The expected value was $50 \%$ of the individuals in each category, and the results were considered significant at $p<0.05$. We also quantified the number of specialist and generalist individuals in each population using the overlap measure, an adaptation of Petraitis' (1979) likelihood approach to measuring species' niche width. The likelihood ratio $\left(L_{i}\right)$ ranges from generalization $(L=1)$ towards specialization $\left(q_{j}\right)$ as an individual specializes on a resource, $j$. However, $L_{i}$ is sensitive to the sample size of diet items consumed by individual $i\left(n_{i}\right)$, and the number of resource categories. Therefore, Petraitis (1979) proposed a standardization procedure, $W_{i}=$ $(L i)^{1 / n i}$, to correct for this sensitivity. Thus, it is possible to test whether the individual's diet represents a significant deviation from that of the population ( $p$ value) (see Bolnick et al. 2002).

The individuals from Saint Peter and Saint Paul and Trindade Archipelagos could not be included in the above analyses because of the smaller number of prey remains and the higher number of shared prey species among octopus dens. $\mathrm{PS}_{i}$ measures have some significant drawbacks, because an individual who consumes items from a single diet category has a score of zero. While this accurately reflects the fact that the individual has a narrow niche, it is not an accurate reflection of that individual's relationship to the population's niche (Bolnick et al. 2002). Since the individuals from these populations nearly always consumed the same prey species, we considered all these individuals as generalists for the correlation analysis.

The relationship between niche width (i.e. diet diversity) and (1) the percentage of specialist individuals in each population relative to habitat diversity, and (2) mean prey size relative to distance from the continental shelf were evaluated using a simple linear regression.

\section{RESULTS}

\section{Diet}

Octopus insularis prey items from the 6 populations were composed mainly of individuals from 3 taxa: Crustacea, Bivalvia and Gastropoda. The main groups collected from the populations at Pirangi, Fernando de Noronha Archipelago, Rocas Atoll and Saint Peter and Saint Paul Archipelago were similar, with crustaceans being the principal diet component (>70\% by number), while prey species from the population at Rio do Fogo were mainly bivalves (>80\%) and those from Trindade Archipelago were mainly gastropods (>90\%) (Fig. 2, Tables 2 \& 3).

We used 2 methods to report prey variation: species richness (Margalef's index), and TNW. For the richness index, the population from Rio do Fogo exhibited the most varied diet, with $D_{\mathrm{Mg}}=4.89$ (379 prey remains from 30 genera: 16 Bivalvia, 8 Gastropoda, 6 Crustacea), followed by Fernando de Noronha Archipelago with $D_{\mathrm{Mg}}=4.15$ (473 prey from 22 genera: 7 Bivalvia, 9 Gastropoda, 6 Crustacea), Rocas Atoll $\left(D_{\mathrm{Mg}}=2.22 ; 473\right.$ prey from 13 genera: 3 Bivalvia, 5 Gastropoda, 5 Crustacea), and Pirangi $\left(D_{\mathrm{Mg}}=2.81 ; 34\right.$ prey from 11 genera: 2 Bivalvia, 3 Gastropoda, 6 Crustacea). The lowest richness was found in Saint Peter and Saint Paul $\left(D_{\mathrm{Mg}}=1.08 ; 16\right.$ prey from 4 genera: all Crustacea $)$ and Trindade Archipelagos $\left(D_{\mathrm{Mg}}=0.80 ; 42\right.$ prey from 4 genera: 1 Bivalvia and 3 Gastropoda). The small number of octopus dens found at these archipelagos despite the high sampling effort (more than 40 dives in $2 \mathrm{yr}$ ) reflects the lower octopus abundance here in

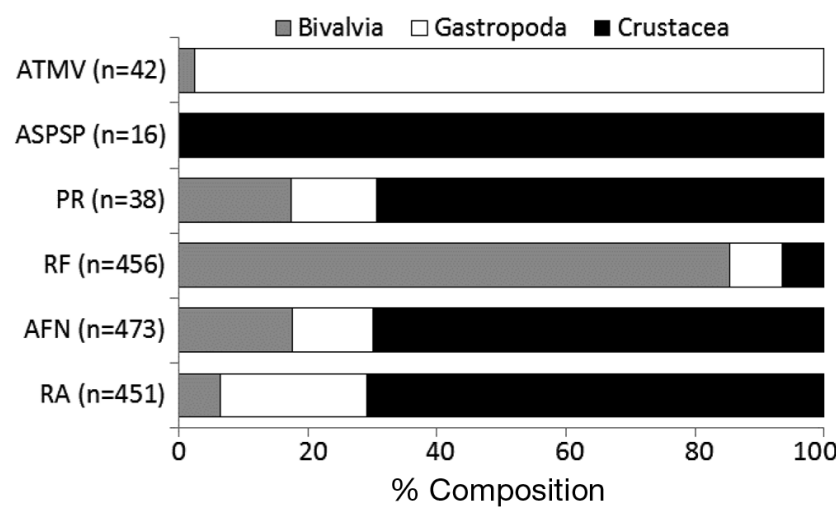

Fig. 2. Composition (by taxonomic category) of the prey remains found around Octopus insularis dens from the sampled areas of Rio do Fogo (RF), Pirangi (PR), Rocas Atoll (RA), Fernando de Noronha Archipelago (AFN), Trindade and Martim Vaz Archipelago (ATMV) and Saint Peter and Saint Paul Archipelago (ASPSP); n: number of prey identified by number of carapaces and shells 
Table 2. Prey items collected from Octopus insularis dens throughout the study area. Pirangi reef (PR): 38 prey items from 12 dens collected in 2011; Rio do Fogo (RF): 456 prey items from 38 dens in 2010 and 2011; Trindade and Martim Vaz Archipelago (ATMV): 42 prey items from 17 dens in 2011 and 2012; Saint Peter and Saint Paul Archipelago (ASPSP): 16 prey items from 13 dens between 2008 and 2011

\begin{tabular}{|c|c|c|c|c|c|c|c|c|c|}
\hline $\begin{array}{l}\text { Site } \\
\text { Prey taxa }\end{array}$ & $\begin{array}{l}\text { Total } \\
\text { number }\end{array}$ & $\%$ & $\begin{array}{c}\text { Den } \\
\text { occurrence }\end{array}$ & $\%$ & $\begin{array}{l}\text { Site } \\
\text { Prey taxa }\end{array}$ & $\begin{array}{c}\text { Total } \\
\text { number }\end{array}$ & $\%$ & $\begin{array}{c}\text { Den } \\
\text { occurrence }\end{array}$ & $\%$ \\
\hline PR & & & & & Bullata matthewsi & 1 & 0.2 & 1 & 2.6 \\
\hline Crustacea & & & & & Astrea latispina & 1 & 0.2 & 1 & 2.6 \\
\hline Xanthodius denticulatus & 10 & 26.3 & 7 & 58.3 & Columbella mercatoria & 1 & 0.2 & 1 & 2.6 \\
\hline Pitho sp. & 7 & 18.4 & 6 & 50.0 & Calliostoma sp. & 1 & 0.2 & 1 & 2.6 \\
\hline Mithrax forceps & 3 & 7.9 & 3 & 25.0 & Cymatium raderi & 1 & 0.2 & 1 & 2.6 \\
\hline Acanthonyx scutiformis & 2 & 5.3 & 1 & 8.3 & Oliva fulgurator & 1 & 0.2 & 1 & 2.6 \\
\hline Epialtus brasiliensis & 2 & 5.3 & 1 & 8.3 & Erosaria acicularis & 1 & 0.2 & 1 & 2.6 \\
\hline Mithrax tortugae & 1 & 2.6 & 1 & 8.3 & Strombus pugilis & 1 & 0.2 & 1 & 2.6 \\
\hline Microphrys sp. & 1 & 2.6 & 1 & 8.3 & Turba canaliculatus & 1 & 0.2 & 1 & 2.6 \\
\hline Bivalvia & & & & & Voluta ebraea & 1 & 0.2 & 1 & 2.6 \\
\hline Arca imbricata & 4 & 10.5 & 2 & 16.7 & Crustacea & & & & \\
\hline Semele sp. & 2 & 5.3 & 2 & 16.7 & Mithrax tortugae & 7 & 1.6 & 5 & 13.2 \\
\hline Gastropoda & & & & & Mithrax sp. & 6 & 1.3 & 3 & 7.9 \\
\hline Pissania pusio & 3 & 7.9 & 1 & 8.3 & Mithrax forceps & 5 & 1.1 & 5 & 13.2 \\
\hline Fissurela sp. & 2 & 5.3 & 1 & 8.3 & Xhantodius denticulatus & 3 & 0.7 & 3 & 7.9 \\
\hline & & & & & Callapa gallus & 3 & 0.7 & 3 & 7.9 \\
\hline Rivalvia & & & & & Chorinus heros & 2 & 0.4 & 2 & 5.3 \\
\hline Anadara notabilis & 129 & 28.3 & 27 & 71.1 & Pitho sp. & 2 & 0.4 & 2 & 5.3 \\
\hline Laevicardium brasilianum & n 56 & 12.3 & 16 & 42.1 & Mithrax tortugae & 1 & 0.2 & 1 & 2.6 \\
\hline Mactra fragilis & 52 & 11.4 & 18 & 47.4 & Michroprys sp. & 1 & 0.2 & 1 & 2.6 \\
\hline Modiolus americanus & 31 & 6.8 & 16 & 42.1 & Cephalopoda & & & & \\
\hline Trachycardium magnum & 28 & 6.1 & 16 & 42.1 & Octopus burryi & 1 & 0.2 & 1 & 2.6 \\
\hline Ventricolaria rigida & 24 & 5.3 & 10 & 26.3 & & & & & \\
\hline Lima lima & 20 & 4.4 & 7 & 18.4 & ATMV & & & & \\
\hline Semele sp. & 18 & 4 & 6 & 15.8 & Bivalvia & & & & \\
\hline Papyridea sp. & 8 & 1.8 & 5 & 13.2 & Chione cancellata & 1 & 2.4 & 1 & 5.9 \\
\hline Arca imbricata & 4 & 0.9 & 4 & 10.5 & Gastropoda & & & & \\
\hline Trigoniocardia media & 3 & 0.7 & 3 & 7.9 & Gastropoda sp. ... & 2 & 4.7 & 1 & 5.8 \\
\hline Americardia media & 2 & 0.4 & 2 & 5.3 & Lithopoma olfersii & 28 & 66.7 & 13 & 76.5 \\
\hline Spondylus ictiricus & 2 & 0.4 & 1 & 2.6 & Nerita ascensionis & 11 & 26.2 & 2 & 11.8 \\
\hline Chlamys sp. & 1 & 0.2 & 1 & 2.6 & & & & & \\
\hline Pinna cornea & 1 & 0.2 & 1 & 2.6 & ASPSP & & & & \\
\hline Tivela fulminatae & 1 & 0.2 & 1 & 2.6 & Malacostraca & & & & \\
\hline Gastropoda & & & & & Mithrax forceps & 6 & 37.5 & 4 & 30.8 \\
\hline Cypraea sp. & 30 & 6.6 & 8 & 21.1 & Plagusia depressa & 3 & 18.8 & 3 & 23 \\
\hline Tonna maculosa & 2 & 0.4 & 2 & 5.3 & Euryozius sanguineus & 5 & 31.3 & 5 & 38.5 \\
\hline Murexiella sp. & 2 & 0.4 & 1 & 2.6 & Xanthodius sp. & 2 & 12.5 & 1 & 7.7 \\
\hline
\end{tabular}

relation to the other areas. In contrast, the low numbers at Pirangi reflected the smallest sampling effort expended at this site.

The continental populations of Rio do Fogo and Pirangi, as well as the Fernando de Noronha Archipelago, had the largest niche widths $(\mathrm{TNW}=2.42$, 2.03 and 2.03, respectively), followed by Rocas Atoll $($ TNW $=1.79)$ (Table 3$)$. The lowest niche widths were exhibited by populations from the most distant oceanic islands (Saint Peter and Saint Paul Archipelago = 1.30; Trindade and Martim Vaz Archipelago = 0.85), where prey items consisted of only 4 crustaceans (Saint Peter and Saint Paul Archipelago), 3 gastropods and 1 bivalve (Trindade and Martim Vaz
Archipelago) (Table 2). The mean sizes of the most numerous prey differed significantly among populations $(F=392$, df $=3, \mathrm{p}<0.001)$, with the exception of the populations from Rocas Atoll and Fernando de Noronha Archipelago ( $p=0.33$ ), and Fernando de Noronha and Pirangi ( $\mathrm{p}=0.09$ ) (Tukey's test: $\mathrm{ms}=$ 15.3, df $=418$ ). Despite this statistical significance, prey size differences were not obvious. The largest prey, Lithopoma sp. (Gastropoda), was found at Trindade and Martim Vaz Archipelago, followed by Anadara notabilis (Bivalvia) at Rio do Fogo (Table 3). Because of the small number of prey remains from Saint Peter and Saint Paul Archipelago, it was not included in the statistical analysis. 


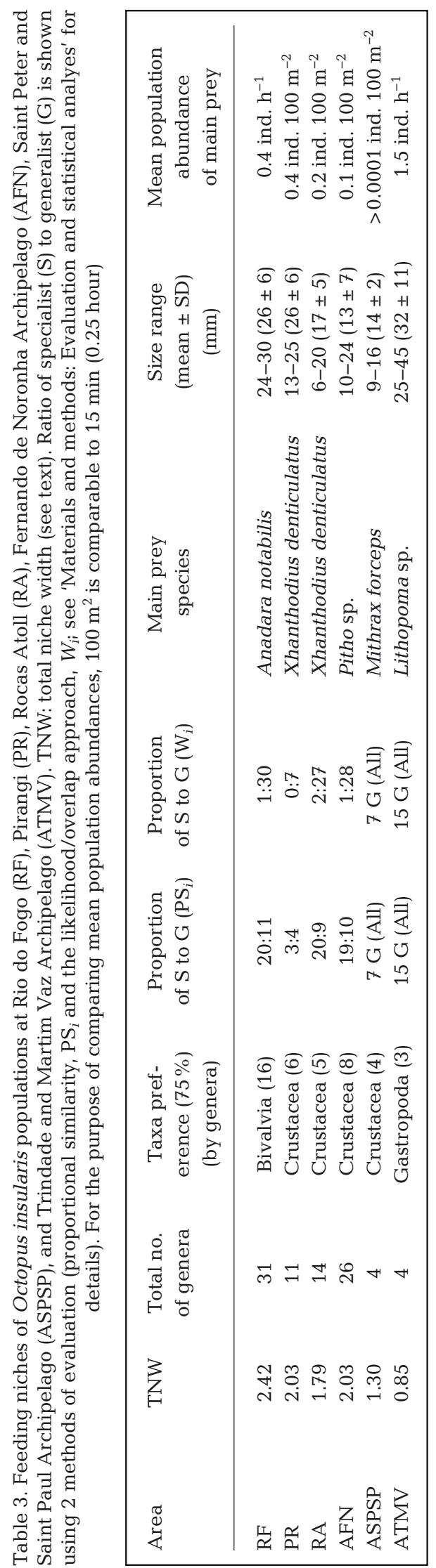

When the sampled areas were compared, significant differences were evident among feeding niches (ANOSIM, R $=0.63$; Fig. 3). The nMDS results showed a greater similarity among Rocas Atoll, Fernando de Noronha and Pirangi based on species abundance, which was confirmed by ANOSIM pairwise tests $(\mathrm{R}<0.5$ between all pairs formed for these 3 areas). Trindade and Martim Vaz Archipelago presented the greatest dissimilarity from the other areas, followed by Rio do Fogo (both with $\mathrm{R}>0.5$ for all pairwise tests) (see Fig. 3). Following the SIMPER analysis, typical genera at each study area ( $>80 \%$ contribution for similarity among samples) were the crustaceans Microphys and Mithrax for Fernando de Noronha archipelago (average similarity, AS, between samples: $37.6 \%$ ), Phito and Cronius for Rocas Atoll (AS $=37.13 \%$ ), Mithrax and Pitho for Pirangi $(\mathrm{AS}=30.23 \%)$, Euryozious and Mithrax for Saint Peter and Saint Paul Archipelago (AS $=42.04 \%$ ), the bivalves Anadara, Americardia, Laevicardium and Modilous for Rio do Fogo ( $\mathrm{AS}=34.2 \%$ ) and the gastropods Nerita and Lithopoma for Trindade and Martim Vaz Archipelago (AS = 67.39).

Rio do Fogo, Rocas Atoll and Fernando de Noronha contained the higher proportion (almost 2 times the amount) of specialist individuals relative to generalists, while Pirangi contained a similar number of specialists and generalists (Table 3 ) based on $\mathrm{PS}_{i}$. However, $W_{i}$ pointed to a lower proportion of specialists than generalists $(<5 \%)$ in all regions, and showed no relationship with habitat diversity $\left(R^{2}=0.1\right)$ (Table 3 ). There was also no significant difference in the proportion of specialists and generalists in each population among octopus size categories using either methodology (chi-squared test, $\mathrm{p}<0.05$ ).

The relationship between habitat diversity in each sampled area (amount of available habitat for hunting) and TNW $\left(\mathrm{R}^{2}=0.84\right)$ and the proportion of specialists (based on $\mathrm{PS}_{i}$ ) in the population was significant $\left(R^{2}=0.63\right)$, and showed that in areas with higher diversity of habitat, the octopus population had a higher niche width and higher proportion of specialist individuals (Fig. 4A). When the $W_{i}$ approach was considered, no relationship between habitat diversity and proportion of specialists was observed $\left(\mathrm{R}^{2}=\right.$ 0.119). On the other hand, the relationship between distance of sampled area from the continental shelf and TNW $\left(\mathrm{R}^{2}=0.89\right)$ was significant, with a decrease in niche width occurring in areas farther away from the continental shelf compared with those closer areas. Mean main prey size was smaller in areas of intermediate distances, and larger in areas further from the coast $\left(R^{2}=0.82\right)$ (Fig. 4B). 


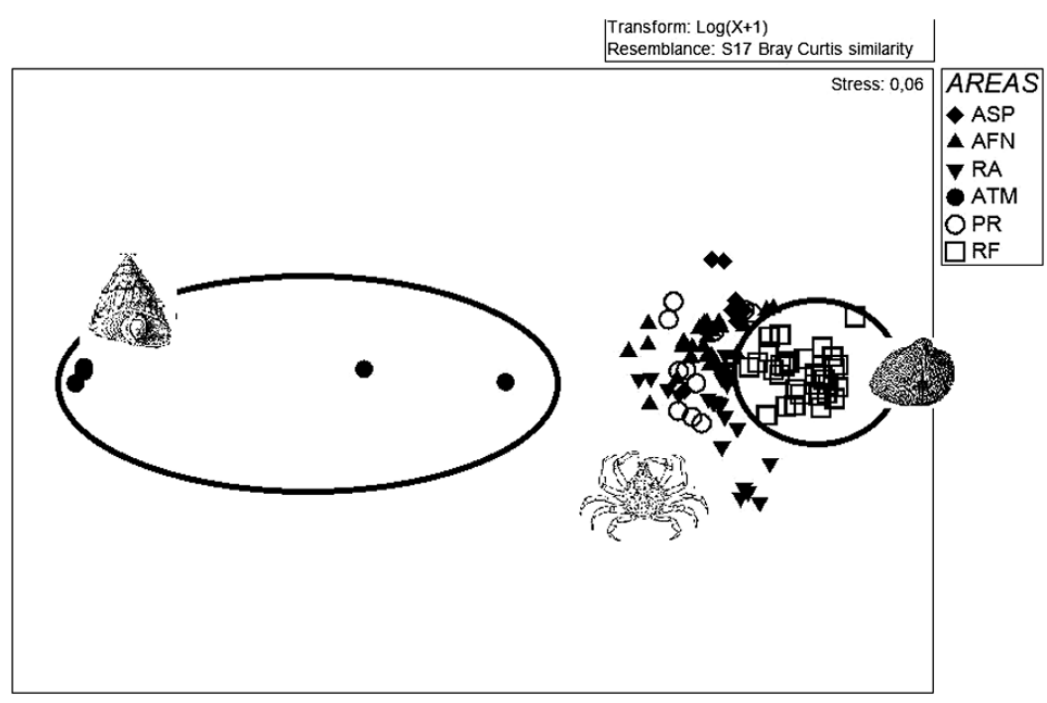

Fig. 3. Multidimensional scaling ordination analysis based on a similarity matrix generated using the Bray-Curtis index, with taxa (genera) and no. ind. taxon ${ }^{-1}$ in each sampled area. RF: Rio do Fogo; PR: Pirangi; RA: Rocas Atoll; AFN: Fernando de Noronha Archipelago; ASP: Saint Peter and Saint Paul Archipelago; ATM: Trindade and Martim Vaz Archipelago
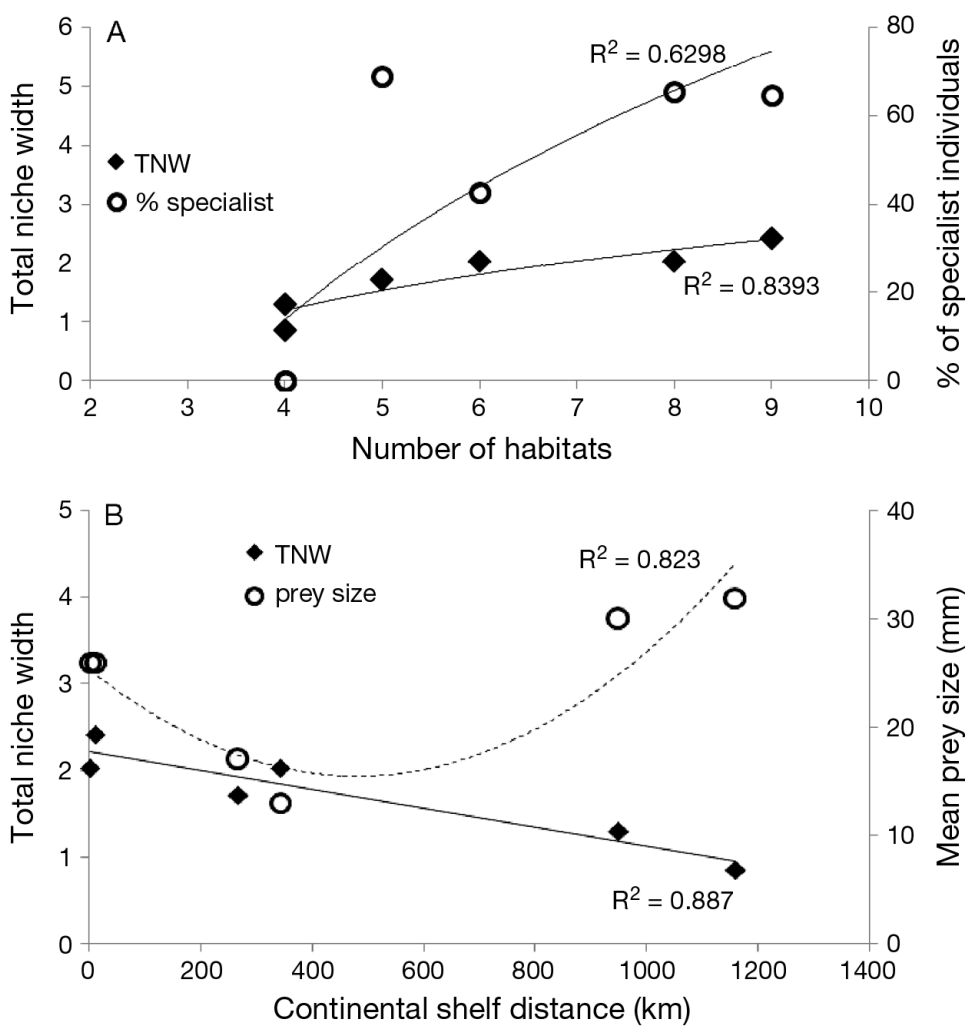

Fig. 4. (A) total niche width (TNW, diet diversity) and percentage of specialist individuals at each Octopus insularis population relative to habitat diversity, and (B) TNW and mean prey size relative to sampled area distance from the continental shelf

\section{DISCUSSION}

In this study, we evaluated the diet of Octopus insularis by examining prey remains collected from middens, since most of the study areas were contained within Marine Preservation Areas, in which there is a ban on capture. This methodology has been shown to be an efficient technique for assessing octopus diet in different countries and with different octopus species (Ambrose 1984, Mather 1991, Scheel et al. 2007, Anderson et al. 2008, Leite et al. 2009b). Moreover, while recent studies that involved digestive tract evaluation, visual captures and midden remains showed that the octopus diet spans a large variety of phyla, these studies still identified crustaceans and molluscs as being the most abundant (Smith 2003, Villegas et al. 2014). Villegas et al. (2014) also reported that unidentified organic matter (representing highly digested prey) was the most common item $(45.8 \%$ frequency of occurrence) in the digestive tract of $O$. bimaculatus, which emphasizes the difficulties involved in identifying prey species using digestive tract methodologies. Based on these arguments, we believe our results accurately reflect the differences among diets of $O$. insularis throughout its geographical range.

Our results indicated that, along the Brazilian coast and oceanic islands, $O$. insularis is an adaptable predator that can act as a specialist or generalist. This behavioral flexibility is partly due to the availability of benthic prey, which is a reflection of the habitat diversity in the area. The density and variety of benthic animals is strongly correlated with the coverage and microhabitat diversity of the ocean bottom, and so the availably of these various substrates is directly reflected in benthic biodiversity and patterns (Nybakken \& Bertness 2004). Based on the theory of island biogeography (MacArthur \& Wilson 1967), oceanic islands are considered to be depleted ecosystems (in terms of both habitat and fauna) compared to continental shelves. Our results were consistent with this, 
showing wide differences in niche breadth and a number of prey species that decreased with distance from the continental shelf.

The similarly large proportion of crustaceans in the diet of $O$. insularis from Rocas Atoll, Fernando de Noronha, and Pirangi correlates with the similar habitat in these areas, which consists mostly of shallow reefs. On the other hand, the higher richness and preference for bivalves rather than crustaceans exhibited by the population from Rio do Fogo (a coastal area with the greatest diversity in habitat) confirms the hypotheses that prey choices are different among different habitat types. The octopuses from the habitat called Restinga (a biogenic reef containing patches of sand, rubble and rock) in Rio do Fogo ate mainly bivalves, while those from the reefs consumed a mix of crustaceans and bivalves (Batista 2012). Nevertheless, the gastropods in the octopuses' diet at the southernmost oceanic archipelago (Trindade) probably reflected the higher availability of these molluscs at this rocky island, as shells of the 2 main species in the diet are also found in high abundance throughout beaches around the main island.

The results presented here are comparable with those reported for other octopus species, which also exhibit variability in diet. In the volcanic island of Azores, Portugal, the common octopus O. vulgaris has a diet consisting mainly of crustaceans (Gonçalves \& Martins 1994), whereas in an area with kelp beds in False Bay, South Africa the diet also includes molluscs (Smith 2003). O. cyanea consumes molluscs and crustaceans in a coralline atoll reef in French Polynesia (Forsythe \& Hanlon 1997), and has a specialist diet consisting of small crustaceans in the shallow reefs of Hawaii (Mather 2011). Enteroctopus dofleini, evaluated with Cardona's niche breadth, also exhibited variability in diet in the eastern Pacific (Scheel \& Anderson 2012).

Heterogeneity in the choice of prey amongst individuals increased as the population had a greater diversity of habitat to explore. However, our results showed a high divergence between the 2 methods of determining individual specialization on a resource. An increasing number of specialists were observed for Rio do Fogo, Rocas Atoll and Fernando de Noronha Archipelago when we used the $\mathrm{PS}_{i}$ index and Mather et al. (2012) evaluation. Anderson et al. (2008) also found a high number of specialists in a diverse habitat in Bonaire, whereas Mather (2011) saw little diversity of prey choice in an apparently similar habitat in Hawaii. However, other factors could also influence prey selection if the octopus has a greater range of choice.
The analysis of diet overlap among the study areas also showed a similar diet between the populations of Rocas Atoll and Fernando de Noronha. However, individuals at Pirangi had a diet more similar to those in the islands than with the population at Rio do Fogo, despite the smaller distance between them. These results reinforce that similarity in available habitats may be more important than geographic location in understanding $O$. insularis prey choice in the northeastern regions. However, when we analyzed the results including the most distant and smaller areas, the prediction of island biogeography was confirmed, with octopuses from Saint Peter and Saint Paul and Trindade and Martim Vaz Archipelagos having the narrowest diet. The southernmost island (Trindade and Martim Vaz Archipelago) showed the most distinct diet. The high density and dominance of the gastropod Lithopoma sp. around these islands (Leite et al. 2012) could drive the octopus population there into a more specialized diet. The species-area association and its relationship with distance from the continent has been confirmed in studies with birds, bats, butterflies, reptiles and amphibians on 19 islands (Ricklefs \& Lovette 1999). In addition, reef fishes from the Atlantic Ocean were found to have the lowest diversity and highest endemism indices in oceanic islands, compared with coastal communities (Floeter et al. 2007). For all these groups, species richness was positively related to island size and the diversity of habitats.

The similarly small size of prey consumed by individuals in the 6 studied populations did not confirm the hypothesis that $O$. insularis would consume larger prey in areas with less diversity. Instead, the dominance of few species in the diet, the relatively small size of the prey consumed, the absence of variation in prey sizes and proportion of generalists and specialists in the octopus size categories confirms the strategy of a time-minimizing predator, as described for the octopuses at Fernando de Noronha Archipelago and Rocas Atoll (Leite et al. 2009b, Bouth et al. 2011), which differs from that of the temperate Enteroctopus dofleini (Scheel et al. 2007). However, our results also show that smaller prey sizes were consumed at sampled areas that were considered to be nurseries for the species (Rocas Atoll and Pirangi) (see Bouth et al. 2011), which contain a higher concentration of juveniles hunting in a specific habitat for smaller prey around the dens. In addition to variation in prey size, octopus body size could also be an important factor in explaining diet variation for some octopus species (Ibánez \& Chong 2008). However, our study considered that the evaluated areas had a 
similar number of octopuses in each size class and therefore were representative of the whole $O$. insularis population for each study area (for details see Leite et al. 2009b, 2012, Batista 2012). The only exception was for the Rocas Atoll population, in which most of the octopuses sampled were classified as small or extra-small size classes (Bouth et al. 2011), and therefore the higher variation in samples from this area could be a result of this characteristic.

We have shown, with information obtained from different populations and habitats, what Ambrose (1984) also reported using comparisons between laboratory choices and field data-that prey choice by octopuses is complex and many-faceted. Clearly, an over-abundance of a particular gastropod species (reflected by the high number of shells and live animals around the island) triggered a choice for that species, but a diversity of available prey also allowed $O$. insularis to select favorites, with a greater variety of choices resulting in a greater diversity of the population's diet, and the presence of specialist individuals. This was perhaps also stimulated by differences among individuals, as found by Anderson et al. (2008) for O. vulgaris. The results of this study are in accordance with MacArthur \& Wilson's (1967) hypothesis of island biodiversity, but also highlights the variability and individual variation in prey choice due to learning by this intelligent animal.

Acknowledgements. We thank the administration of Fernando de Noronha and the Chico Mendes Institute (ICMBio) at Fernando de Noronha and Rocas Atoll, and the Interministerial Commission for Sea Resources (CIRM) for their logistic support; we are also thankful to the volunteers and students who helped collect field samples. The information used in this study was supported by the Foundation Boticário for Environmental Protection (057720031) and by the National Council of Technological and Scientific Development, CNPq (CNPq 558467/2005-9, 559863/2008-0, $557154 / 2009-0)$, which funded many of the scientific expeditions to the oceanic island and projects along the coast, and the Study Leave visit by Dr. Jennifer Mather (APV 455579/2010-5) to the Federal University of Rio Grande do Norte. We thank 2 anonymous reviewers and Dr. David Scheel for their assistance in improving the quality of this manuscript.

\section{LITERATURE CITED}

Ambrose RF (1984) Food preferences, prey availability, and the diet of Octopus bimaculatus Verrill. J Exp Mar Biol Ecol 77:29-44

> Anderson RC, Wood JB, Mather JA (2008) Octopus vulgaris in the Caribbean is a specializing generalist. Mar Ecol Prog Ser 371:199-202

Batista TA (2012) Caracterização do nicho alimentar do polvo Octopus insularis (Cephalopoda: Octopodidae): da população ao indivíduo. MSc dissertation, Universidade Federal do Rio Grande do Norte, Natal

Bolnick DI, Yang LH, Fordyce JA, Davis JM, Svanbäck R (2002) Measuring individual-level resource specialization. Ecology 83:2936-2941

Bouth HF, Leite TS, Lima FD, Lins-Oliveira JE (2011) Atol das Rocas: an oasis for Octopus insularis juveniles (Cephalopoda: Octopodidae). Zoologia 28:45-52

Bray JR, Curtis JT (1957) An ordination of the upland forest communities of southern Wisconsin. Ecol Monogr 27: 325-349

Clarke KR, Warwick RM (2001) Changes in marine communities: an approach to statistical analysis and interpretation. Primer-E, Plymouth

Darmaillacq AS, Dickel L, Mather JA (2014) Cephalopod cognition. Cambridge University Press, Cambridge

Floeter SR, Rocha LA, Robertson DR, Joyeux JC and others (2007) Atlantic reef fish biogeography and evolution. J Biogeogr 35:22-47

Forsythe JW, Hanlon RT (1997) Foraging and associated behavior by Octopus cyanea Gray, 1849 on a coral atoll, French Polynesia. J Exp Mar Biol Ecol 209:15-31

> Gaston KJ (2000) Global patterns in biodiversity. Nature 405:220-227

Gonçalves JM, Martins HR (1994) Despojos alimentares encontrados em abrigos de polvo comum (Octopus vulgaris) (Mollusca: Cephalopoda) do Faial (Açores): dados preliminares. Rel Com Dep Biol 22:29-33

Gosling E (2003) Bivalve molluscs: biology, ecology and culture. Blackwell Science, London

Hammer $\varnothing$, Harper DAT, Ryan PD (2001) PAST: paleontological statistics software package for education and data analysis. Paleontol Electronica 4(1):1-9

Ibáñez CM, Chong JV (2008) Feeding ecology of Enteroctopus megalocyathus (Cephalopoda: Octopodidae) in southern Chile. J Mar Biol Assoc UK 88:793-798

Jaksi FM (1989) Opportunism vs. selectivity among carnivorous predators that eat mammalian prey: a statistical test of hypotheses. Oikos 56:427-430

Karleskint G, Turner R, Small J (2010) Introduction to marine biology. Brooks/Cole, Belmont, CA

Leite TS, Haimovici M, Molina W, Warnke K (2008) Morphological and genetic description of Octopus insularis, a new cryptic species in the Octopus vulgaris complex (Cephalopoda: Octopodidae) from the tropical southwestern Atlantic. J Molluscan Stud 74:63-74

Leite TS, Haimovici M, Mather J, Lins-Oliveira JE (2009a) Habitat, distribution, and abundance of the commercial octopus (Octopus insularis) in a tropical oceanic island, Brazil: information for management of an artisanal fishery inside a marine protected area. Fish Res 98:85-91

Leite TS, Haimovici M, Mather J (2009b) Octopus insularis (Octopodidae), evidences of specialized predator and a time-minimizing hunter. Mar Biol 156:2355-2367

Leite TS, Barbosa JC, Almeida LB, Lima FD, Haimovici M (2012) Occurrence of Octopus insularis and observations on its feeding and mating in Trindade and Martim Vaz Archipelagos of southeastern Brazil. Cephalopod International Advisory Council Symposium, Florianopolis

MacArthur R, Wilson EO (1967) The theory of island biogeography. Princeton University Press, Princeton, NJ

Mather JA (1991) Foraging, feeding and prey remains in middens of juveniles Octopus vulgaris (Mollusca: Cephalopoda). J Zool (Lond) 224:27-39

Mather JA (2011) Why is Octopus cyanea Gray in Hawaii 
specializing in crabs as prey? Vie Milieu 61:181-184

Mather JA, Anderson RC (1993) Personalities of octopuses (Octopus rubescens). J Comp Psychol 107:336-340

Mather JA, Leite TS, Batista AT (2012) Octopus prey choice: evaluation of the generalist-specialist spectrum. Curr Zool 58:596-602

Mather JA, Leite TS, Anderson RC, Wood JB (2014) Foraging and cognitive competence in octopuses. In: Darmaillacq AS, Dickel L, Mather, JA (eds) Cephalopod cognition. Cambridge University Press, Cambridge, p 125-149

Melo GAS (1996) Manual de identificação dos Brachyura (caranguejos e siris) do litoral brasileiro. Plêiade/FAPESP, São Paulo

Nixon M (1987) Cephalopod diets. In: Boyle PR (ed) Cephalopod life cycles II: Comparative reviews. Academic Press, London, p 201-219

Nybakken JW, Bertness M (2004) Marine biology: an ecological approach. Pearson Education, San Francisco, CA

Onthank KL, Cowles DL (2011) Prey selection in Octopus rubescens: possible roles of energy budgeting and prey nutritional composition. Mar Biol 158:2795-2804

Petraitis PS (1979) Likelihood measures of niche breadth and overlap. Ecology 60:703-710

Ricklefs RE, Lovette IJ (1999) The roles of area per se and habitat diversity in the species-area relationships of four

Editorial responsibility: Roger Villanueva,

Barcelona, Spain
Lesser Antillean faunal groups. J Anim Ecol 68:1142-1160 Rios EC (1994) Seashells of Brazil. FURG, Rio Grande

Roughgarden J (1979) Theory of population genetics and evolutionary ecology: an introduction. Macmillan, New York, NY

Scheel D, Anderson R (2012) Variability in the diet specialization of Enteroctopus dofleini (Cephalopoda: Octopodidae) in the Eastern Pacific examined from midden contents. Am Malacol Bull 30:267-279

Scheel D, Lauster A, Vincent TLS (2007) Habitat ecology of Enteroctopus dofleini from middens and live prey surveys in Prince William Sound, Alaska. In: Landman NH, Davis RA, Mapes RH (eds) Cephalopods present and past: new insights and fresh perspectives. Springer, Dordrecht, p 434-455

Schoener TW (1968) The Anolis lizards of Bimini: resource partitioning in a complex fauna. Ecology 49:704-726

Smith CD (2003) Diet of Octopus vulgaris in False Bay, South Africa. Mar Biol 143:1127-1133

Stephens DW, Brown JS, Brown RC (2007) Foraging: behavior and ecology. University of Chicago Press, Chicago, IL

> Villegas EJA, Ceballos-Vázquez BP, Markaida U, AbitiaCárdenas A, Medina-López MA, Arellano-Martínez M (2014) Diet of Octopus bimaculatus Verrill, 1883 (Cephalopoda: Octopodidae) in Bahia de Los Ángeles, Gulf of California. J Shellfish Res 33:305-314

Submitted: November 4, 2014; Accepted: April 11, 2016

Proofs received from author(s): May 7, 2016 